\title{
Impact of a household-level deductible on prescription drug use among lower-income adults: a quasi-experimental study
}

\author{
Michael R. Law PhD, Lucy Cheng MSc, Heather Worthington MSc, Sumit R. Majumdar MD MPH, \\ Kimberlyn M. McGrail PhD, Fiona Chan MSc, Tracey-Lea Laba PhD, \\ Muhammad Mamdani PharmD MPH
}

\section{Abstract}

Background: Several Canadian public drug plans have income-based deductibles, but we have limited data on their impact, particularly for vulnerable populations. Therefore, we studied the impact of deductibles in British Columbia's Fair PharmaCare program on drug use among lower-income adults.

Methods: We used a quasi-experimental regression discontinuity design to study the impact of BC rules that impose no deductible before receiving public coverage on households with incomes less than $\$ 15000$, a deductible of $2 \%$ of household income on those with incomes between $\$ 15000$ and $\$ 30000$, and a deductible of $3 \%$ of household income on those with incomes above $\$ 30000$. We studied the impact of these thresholds on public and total drug expenditures between 2003 and 2015 using 24 million personyears of data.

Results: Both thresholds decreased the proportion of beneficiaries receiving benefits, by 0.33 ( $95 \%$ confidence interval [Cl] -0.34 to $-0.30)$ and $0.05(95 \% \mathrm{Cl}-0.064$ to -0.032$)$ respectively. There were also substantial reductions in the extent of public drug plan expenditures $(\$ 59.94[95 \% \mathrm{Cl}-74.74$ to -45.14 ] and $\$ 26.12$ [95\% Cl -39.78 to -12.46$]$, respectively). The change at the $\$ 15000$ threshold reduced patient drug expenditures by $\$ 26.00(95 \% \mathrm{Cl}-45.48$ to -6.51$)$, or $7.2 \%$. In contrast, we found no statistically significant change in total expenditures when households moved from a deductible of $2 \%$ to $3 \%$ at the $\$ 30000$ threshold.

Interpretation: Income-based deductibles considerably affected the extent of public subsidy for prescription drugs. For lower-income households making around $\$ 15000$, the deductible led to a reduction of $7.2 \%$ in overall drug use and costs. Although deductibles are a useful tool to limit public expenditures, policy-makers should be cautious in their use among vulnerable populations.

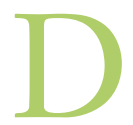

rug coverage in Canada varies widely despite universal coverage for physician and hospital services. ${ }^{1}$ Some provinces, including British Columbia, Saskatchewan, Manitoba, and Newfoundland and Labrador, provide coverage through so-called income-based coverage programs. These programs require households to spend a fixed proportion of their household income on prescription drugs before public coverage takes effect. Other provinces have coverage programs that include deductibles for particular segments of the population, such as Ontario's Trillium Program for residents aged 25-64 years.

We know from prior surveys that cost-related nonadherence remains an issue for many Canadians. ${ }^{2}$ Furthermore, the use of deductibles is potentially problematic, as there is extensive evidence, from both Canada and other countries, that out-of-pocket copayments reduce the use of essential drugs. ${ }^{3-5}$ However, the specific impact of income-based deductibles remains less clear. For example, an analysis done shortly after BC's income-based plan Fair PharmaCare was implemented, in 2003, suggested the plan did not alter population-level prescription drug use, ${ }^{6}$ whereas, evidence from Manitoba suggested that income-based deductibles decreased the use of inhaled corticosteroids by children with asthma. ${ }^{7}$ Yet as with the BC study, the prior coverage regimen in Manitoba included a deductible per family. ${ }^{7}$ Our recent study using a

Competing interests: Michael Law has consulted for Health Canada and the Hospital Employees' Union, and acted as an expert witness for the Attorney General of Canada. Muhammad Mamdani has served as an advisory board member for AstraZeneca, Bristol-Myers Squibb Canada, Eli Lilly and Company, GlaxoSmithKline, Hoffmann-La Roche, Novartis Pharmaceuticals Canada, Novo Nordisk and Pfizer Canada. No other competing interests were declared.

This article has been peer reviewed.

Correspondence to: Michael Law, michael.law@ubc.ca CMAJ Open 2019. DOI:10.9778/cmajo.20180198 
regression discontinuity design showed that income-based deductibles did not affect overall use of drugs or health care services. ${ }^{8}$ That study, however, focused on older adults, and, therefore, the results may not be generalizable to other segments of the population.

The implications of the existing evidence on the impact of income-based deductibles on drug use for specific populations in Canada are unclear. Prior work in the United States showed that deductibles can reduce expenditures, but it is unclear for whom. ${ }^{9}$ This uncertainty has led to a major debate on the role that income-based deductibles should play in Canadian drug plans. For example, although a report from the Institute for Research on Public Policy indicated that Fair PharmaCare should not be emulated in other provinces, ${ }^{10}$ other bodies such as the C.D. Howe Institute have recommended it as a model policy for reforming Ontario's public drug plan. ${ }^{11}$ One important aspect of this debate is the degree to which government can offset expenditures while minimizing the impact on patients. To help inform this debate, we studied the impact of 2 thresholds in BC's Fair PharmaCare using a strong observational study design with a particular focus on lower-income adults.

\section{Methods}

\section{Context}

British Columbia offers residents public drug coverage through the Fair PharmaCare program, which provides drug coverage to all residents with a deductible that is based on household income. The plan covers a comprehensive list of prescription drugs. Fair PharmaCare deductibles are determined based on net household income, verified by the Canada Revenue Agency, from 2 years prior. The program operates alongside universal hospital and physician coverage for medically necessary services that does not use patient copayments.

Our study leveraged "breaks" in coverage created by 2 changes in the deductible structure of Fair PharmaCare. One such break occurs at \$15 000, where households move from having no deductible to having a deductible equivalent to $2 \%$ of household income. A second break, at \$30 000, requires households to spend $3 \%$ of net household income before receiving public coverage. Beyond these thresholds, households must pay $30 \%$ of the cost of prescription drugs up to a household maximum of $3 \%$ and $4 \%$, respectively. These 2 thresholds introduce substantial discontinuities into the out-of-pocket obligations for households just below and just above these 2 income levels (Appendix 1, available at www. cmajopen.ca/content/7/1/E167/suppl/DC1). For instance, a household with a total income of $\$ 14999$ would have no deductible and pay a maximum of $\$ 300$ per year, whereas one with an income of $\$ 15000$ would have a $\$ 300$ deductible and pay a maximum of $\$ 450$.

\section{Data sources}

We obtained data from the BC PharmaNet system, a population-based administrative data system on drug dispensations in BC between 2003 and 2015. As all community pharmacies are required to submit claims through this system, the database is highly accurate and complete, capturing all drug dispensations in the community setting in real time. Using PharmaNet, we captured data on individual prescriptions, including drug information, total cost and the publicly paid portion.

\section{Population}

Our study focused on a population-based open cohort of people eligible for BC Fair PharmaCare coverage during the study period. We included only those who registered for Fair PharmaCare, as household income data were not available for nonregistered households. In fiscal 2016/17, 1253497 families, representing about two-thirds of BC's 1881970 households, ${ }^{12}$ were registered for Fair Pharmacare. ${ }^{13}$ People who received drug benefits through the federal government were also excluded as they would not have been subject to the same program rules.

This analysis included all enrollees who were consistently eligible for the standard Fair PharmaCare benefit (known as Plan I) in each calendar year and for whom verified income information was available. Given the structure of Fair PharmaCare, this would include only people born after 1939, as those born in 1939 or earlier would have been eligible for so-called enhanced assistance, which had lower deductibles. Plan I is the largest of BC's pharmacare programs and is open to all BC residents. Other pharmacare programs are available for people receiving social assistance, those with particular illnesses and those in residential care facilities. ${ }^{13}$ Importantly for this analysis, Plan I is the only program that includes the described deductibles. We focused our analysis on households with incomes of \$61 667 or less. We chose this threshold as it represented the top end of the income bracket that was double the $\$ 30000$ threshold. We defined this a priori and assumed it would give us enough points to fit a smooth line without being unduly influenced by higher income levels. As we could obtain only 1 of the 25 different Fair PharmaCare income bands for each person, we assigned each person the midpoint income within each Fair PharmaCare plan code for all analyses (e.g., we used \$22 500 for Plan Code IB, which includes households with incomes between \$21 250 and \$23 750).

The unit of analysis was the person-year. We excluded any residents who had claims under any other Fair PharmaCare plan (B, C, D, F, G or P) during the year(s) in question to limit potential contamination from other plans that do not impose the same deductible structure. We also excluded person-years in which the person changed income bands during the year in question.

\section{Outcome measures}

We studied the impact of income-based deductibles on outcomes within 2 broad categories:

- System-level outcomes: We calculated the proportion of enrollees in each income band per person-year to estimate the impact of deductibles on the proportion receiving any public drug plan benefits. Second, we calculated the 
average amount paid by the public Fair PharmaCare program per person-year to estimate the impact of deductibles on the extent of public plan spending.

- Patient-level outcomes: We calculated the average total prescription drug expenditure (including both public and private portions), the average number of prescriptions dispensed and the number of unique medicines (based on Anatomical Therapeutic Chemical Classification System level 7 codes) per person-year in our cohort.

\section{Statistical analysis}

We used a regression discontinuity analysis, one of the strongest quasi-experimental research designs, to study the impact of deductibles on our outcomes. ${ }^{14,15}$ This method leverages the quasi-random nature of the change in program design at the $\$ 15000$ and $\$ 30000$ household income thresholds to derive causal estimates of real-world impacts. ${ }^{16}$ As people on either side of these thresholds are likely similar on other characteristics, any abrupt differences in their drug use may be attributed to the effects of the plan design. The major assumption in such an analysis is that all potential confounders do not have abrupt changes across this threshold. Regression discontinuity designs have a long history in economics, and their use is increasing within the medical literature. ${ }^{17,18}$

To fit our statistical models, we first determined the average for each outcome across all person-years in our data set within each income band. As the use of deductibles varied based on household income, this was the forcing variable in our models. Using these aggregate figures, we fit linear regression models that included breaks at both thresholds, as well as linear and quadratic trend parameters within each group:

Outcome $=\beta_{0}+\beta_{1} \cdot X_{i}+\beta_{2} \cdot X^{2}{ }_{i}+\beta_{3}\left[X_{i}>15000\right]+\beta_{4}\left(X_{i}-\right.$ $15000) \cdot\left[X_{i}>15000\right]+\beta_{5}\left(X_{i}-15000\right) \cdot\left[X_{i}>15000\right]^{2}+\beta_{6}\left[X_{i}>\right.$ $30000]+\beta_{7}\left(X_{i}-30000\right) \cdot \beta_{8}\left(X_{i}-30000\right) \cdot\left[X_{i}>30000\right]^{2}+\varepsilon_{i}$

where $X$ represents the forcing variable of household income, and 15000 and 30000 represent the 2 cut-off points. The parameters of interest from the regression results are $\beta_{3}$, which represents the change in the outcome at the $\$ 15000$ income threshold, and $\beta_{6}$, which represents the change in the outcome at the $\$ 30000$ threshold.

\section{Ethics approval}

The study was approved by the University of British Columbia Behavioural Research Ethics Board.

\section{Results}

\section{Cohort characteristics}

After we excluded 11420158 person-years with income greater than $\$ 61$ 666, our final cohort consisted of 12706804 personyears contributed by 2178162 unique individuals. The cohort had slightly more females than males (51.6\% v. 48.4\%), and the average age of people in their first year in the cohort was 38.1 years. The mean number of prescriptions dispensed per year was 6.7 (Table 1).

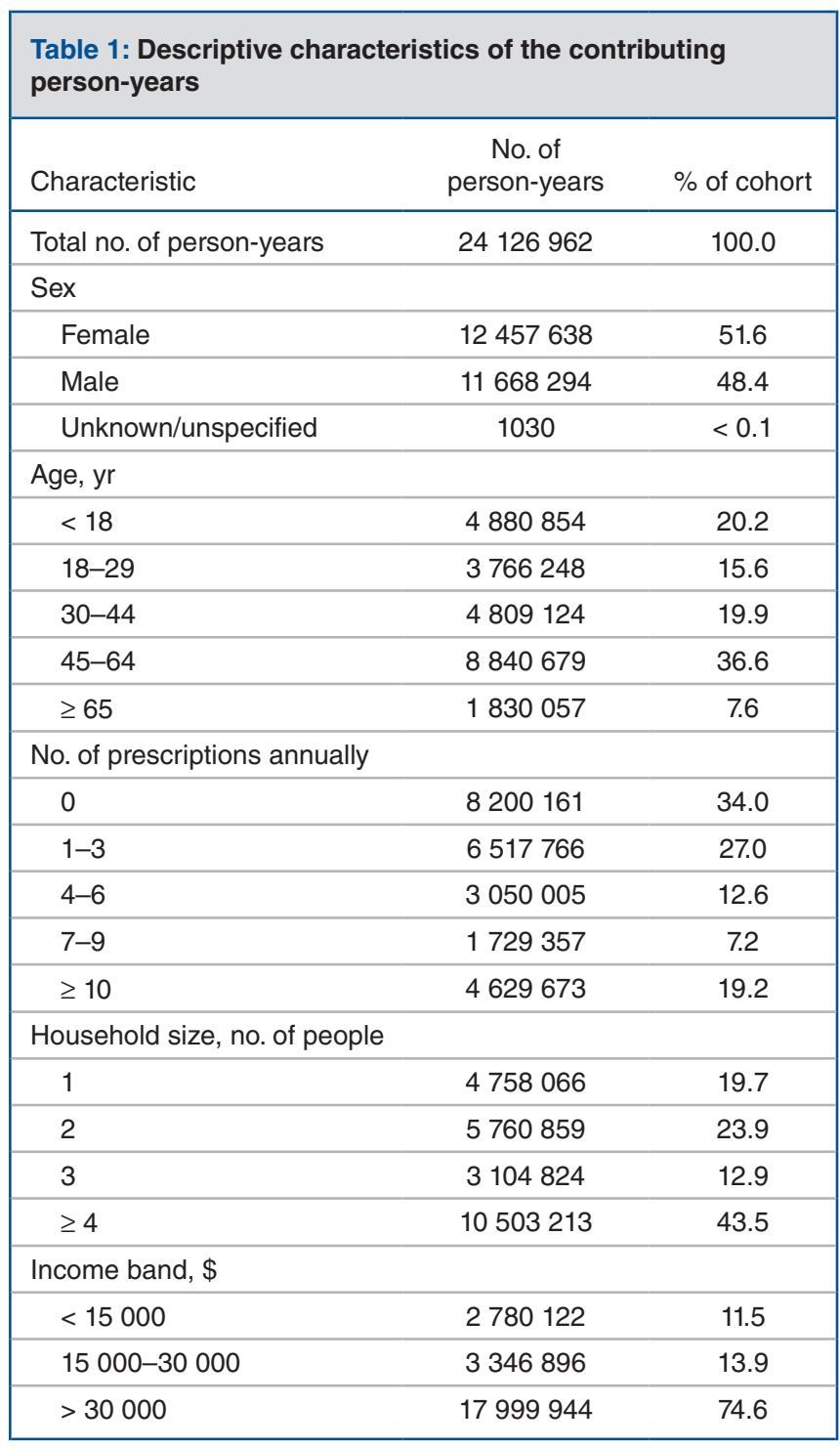

\section{System-level outcomes}

Analysis of the proportion of enrollees receiving Fair PharmaCare benefit payments showed that the move from no deductible to a deductible of $2 \%$ of household income led to an absolute decrease of $33 \%$ (95\% CI -0.34 to -0.30$)$ in the proportion of enrollees receiving public benefits, from $54 \%$ to $21 \%$ (Figure 1). This represents a relative decrease of $61 \%$. We found a smaller reduction $(5 \%, 95 \% \mathrm{CI}-0.064$ to -0.032$)$ in the proportion receiving benefits at the $\$ 30000$ threshold, from $18 \%$ to $13 \%$.

Consistent with this decrease in the proportion receiving benefits, we found substantial decreases in the extent of public drug plan expenditures across the 2 income thresholds. There was a reduction of $\$ 59.94(95 \% \mathrm{CI}-74.74$ to -45.14$)$ in the mean annual Fair PharmaCare reimbursement at the $\$ 15000$ threshold, representing a relative decrease of $27 \%$, and a decrease of $\$ 26.12$ (95\% CI -39.78 to -12.46 ) at the $\$ 30000$ threshold (Figure 2). 


\section{Research}

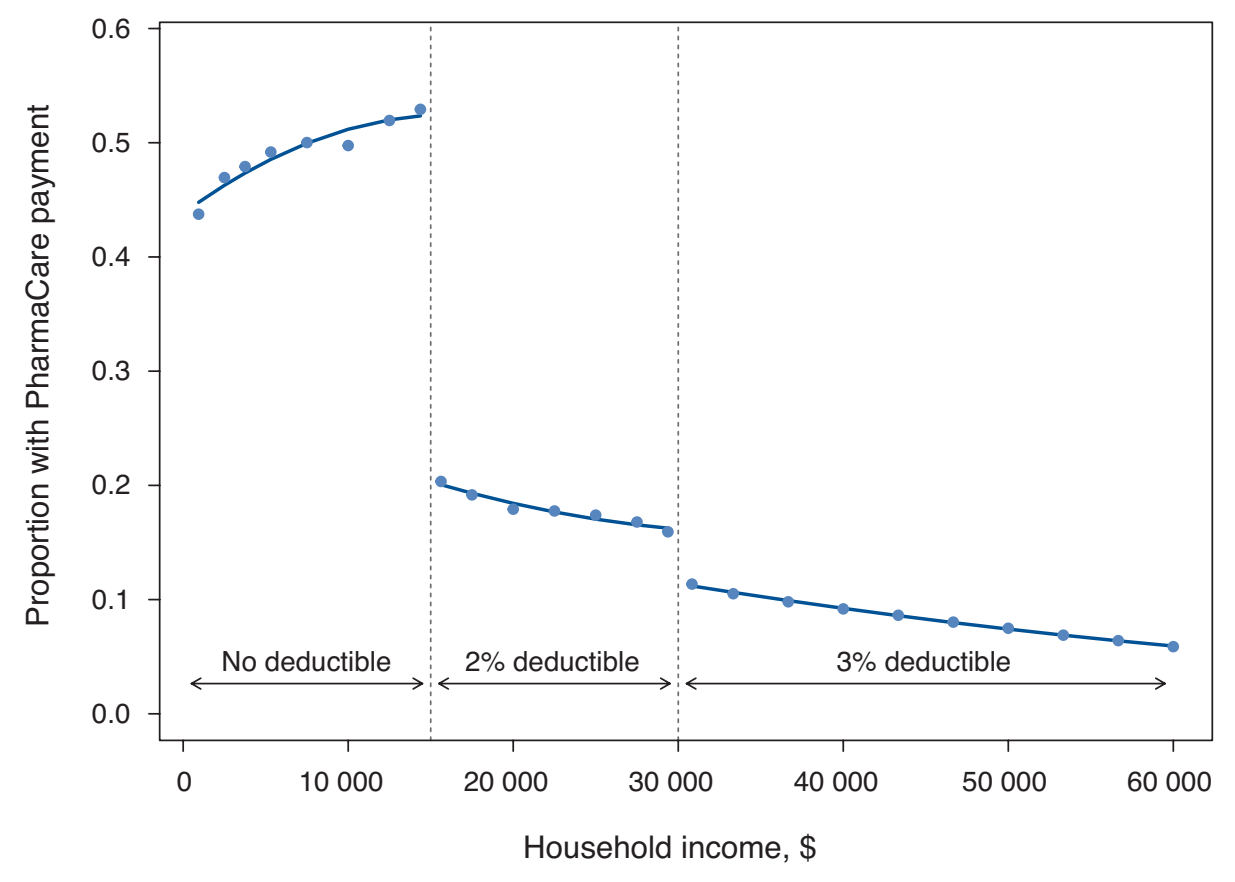

Figure 1: Regression discontinuity analysis across income thresholds of mean proportion of beneficiaries with a claim where Fair PharmaCare paid a portion.

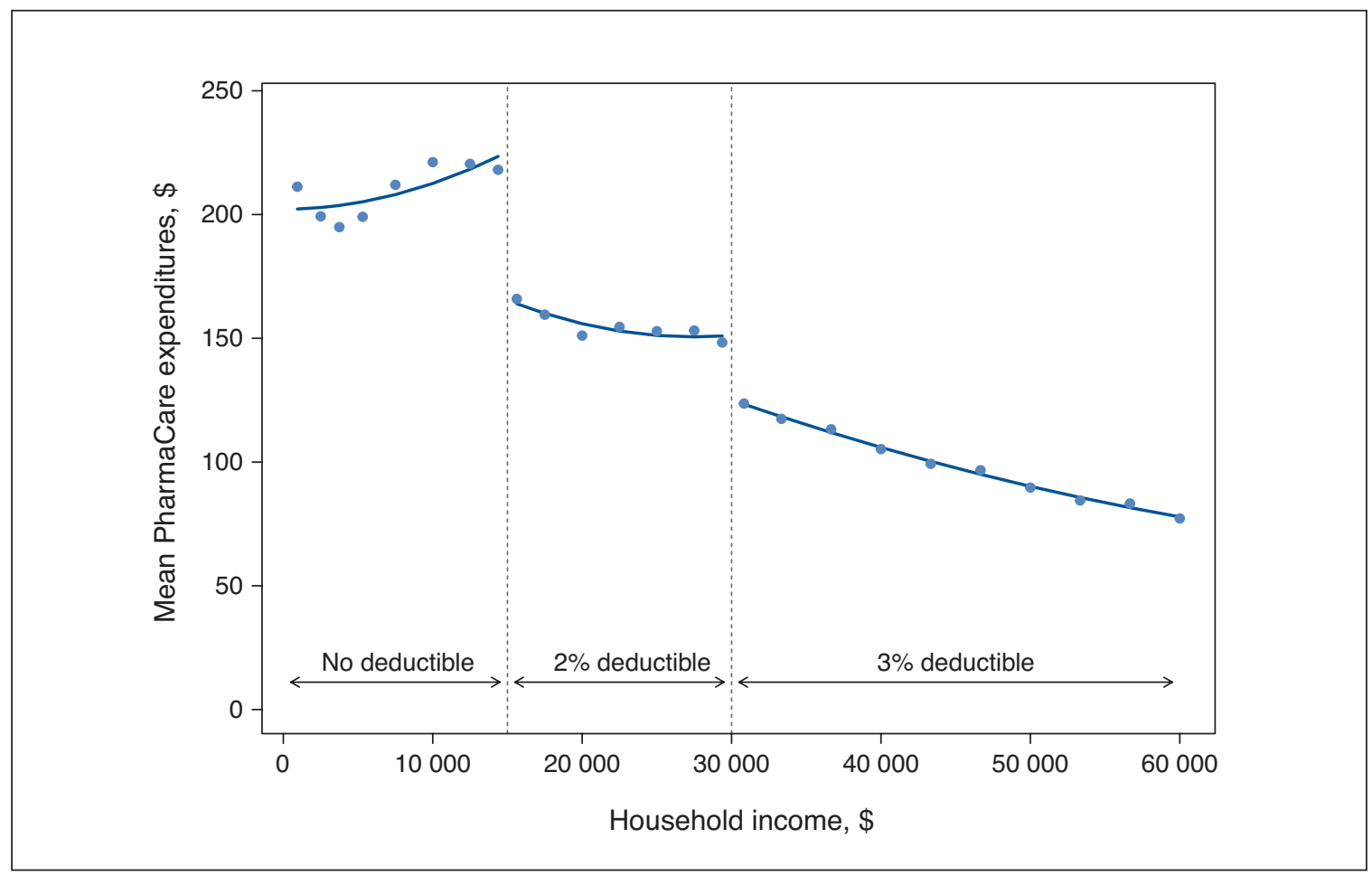

Figure 2: Regression discontinuity analysis of mean annual drug expenditures by the Fair PharmaCare program across income thresholds.

\section{Patient-level outcomes}

In comparison to the large difference in public subsidies, we found smaller changes in patient drug use and costs at the
2 income thresholds. There was a reduction of \$26.00 (95\% CI -45.48 to -6.51 ) in annual total drug expenditures at the $\$ 15000$ threshold (Figure 3). This represented an absolute 


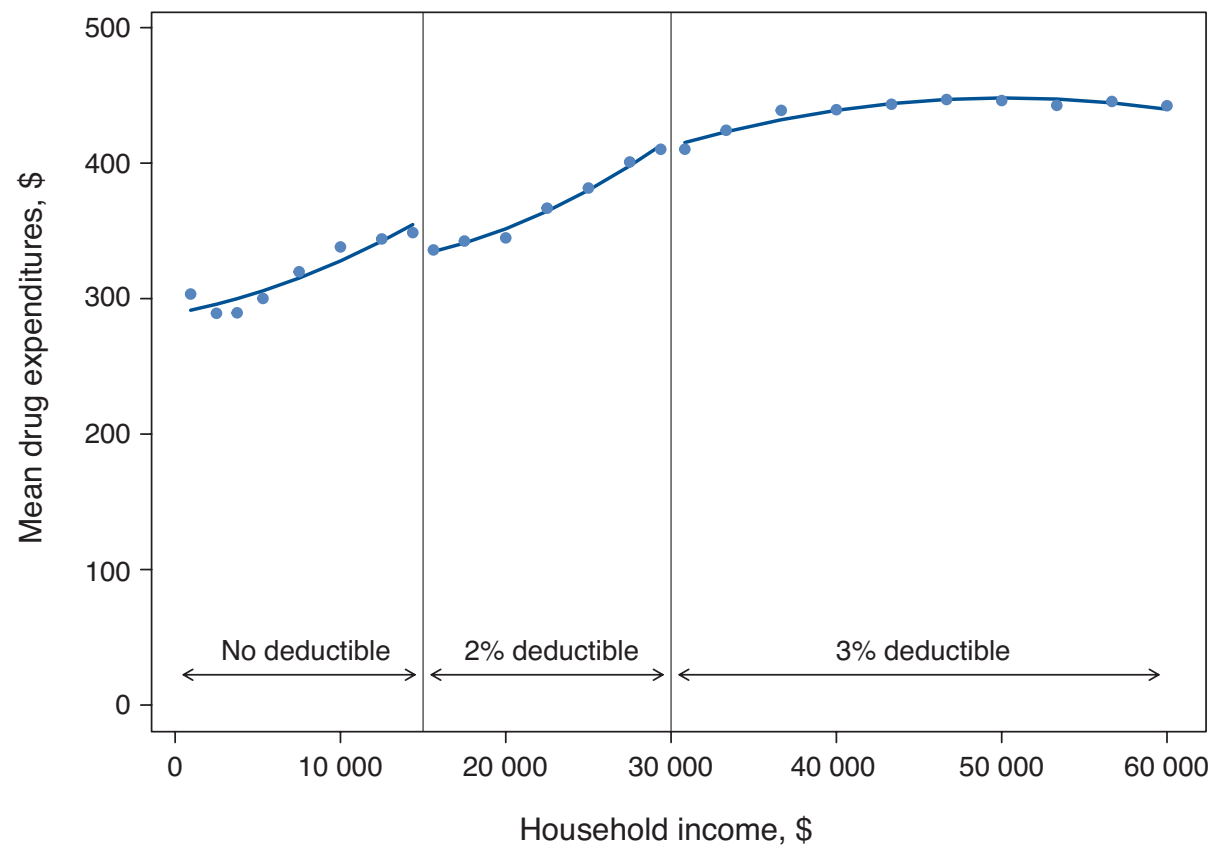

Figure 3: Regression discontinuity analysis of average total prescription drug expenditure above and below the income thresholds.

decrease of $7.2 \%$ in total expenditures when households moved across the threshold from no public drug plan deductible to a deductible of $2 \%$ of household income. In contrast, we found no statistically significant change in total expenditures when households moved from deductibles of $2 \%$ to $3 \%$ of household income at the $\$ 30000$ threshold (estimate $\$ 6.10,95 \%$ CI -24.08 to 11.89 ).

Analysis of total prescriptions showed only small reductions in the average number of individual prescriptions received. We found nonsignificant reductions of 0.35 prescriptions (95\% CI -0.79 to 0.09 ) at the $\$ 15000$ threshold and 0.14 prescriptions (95\% CI -0.54 to 0.267 ) at the $\$ 30000$ threshold (Figure 4). We also found a small decrease in the number of unique medicines received: the average annual number of unique drugs filled above and below the $\$ 15000$ thresholds was reduced by 0.07 drugs $(95 \%$ CI -0.12 to -0.03$)$ per beneficiary, an absolute decrease of $4.8 \%$ (Figure 5 ). We found no significant change in the number of unique medicines received at the $\$ 30000$ threshold (estimate $0.00,95 \% \mathrm{CI}-0.04$ to 0.04 ).

\section{Interpretation}

In this quasi-experimental study of the impact of householdlevel deductibles on drug use, we found that, for lower-income households with incomes around $\$ 15000$, deductibles led to a notable reduction in the proportion of beneficiaries who receive any public subsidy, as well as in overall drug use and costs. In contrast, once at an income of $\$ 30000$, a move from a deductible of $2 \%$ of household income to $3 \%$ of household income appeared to have no notable impact on these same outcomes.
Our results suggest that the impact of deductibles differs between different populations in BC. In contrast, our prior study examining a very similar change from no deductible to a deductible of $2 \%$ of household income for those born in 1939 or earlier and after 1939 showed no change in overall drug use. ${ }^{8}$ Although the population in that study had incomes just above the threshold in the present study (\$15 000-\$30 000), we believe that the major difference is the age of the populations under study - an average age of 66 years in the prior study versus 38 years in the present study. This is consistent with differences in cost-related nonadherence reported in a survey study, in which younger populations consistently reported more issues in affording their prescription drugs than did older populations. ${ }^{19}$ Our lack of an impact of the change from a deductible of $2 \%$ of household income to $3 \%$ of household income at $\$ 30000$ suggests that, beyond a certain income level, marginal changes in the deductible may not be major determinants of drug access.

\section{Limitations}

As with any analysis of administrative claims data, our study has several limitations worth noting. First, we did not have data on the clinical indication for the prescriptions that were written, nor did we have information on the characteristics of prescriptions that were foregone by people at different income levels. Furthermore, we lacked data on the presence or lack of private drug insurance held by the person in question or another person such as a spouse. This is a major missing factor in our analysis, particularly as private insurance would insulate them from paying the Fair PharmaCare 


\section{Research}

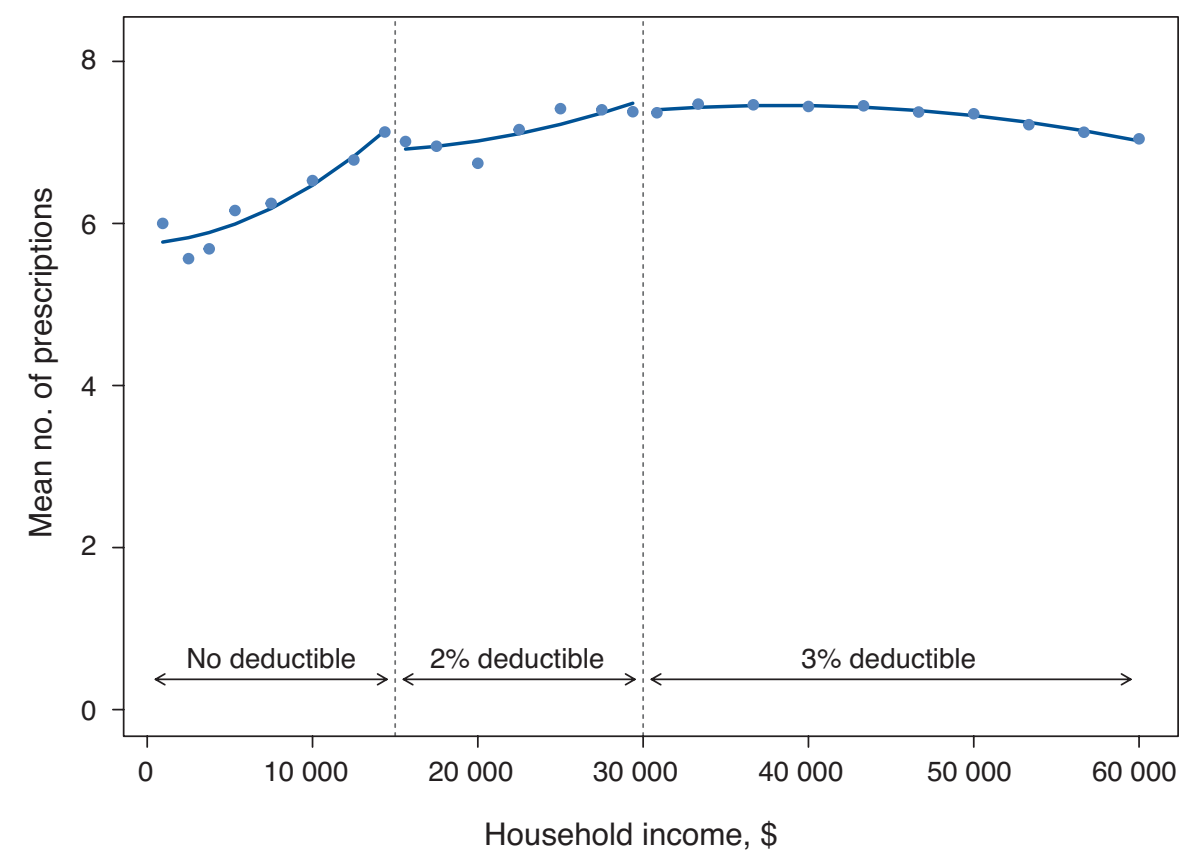

Figure 4: Regression discontinuity analysis of average annual number of prescriptions filled above and below the income thresholds.

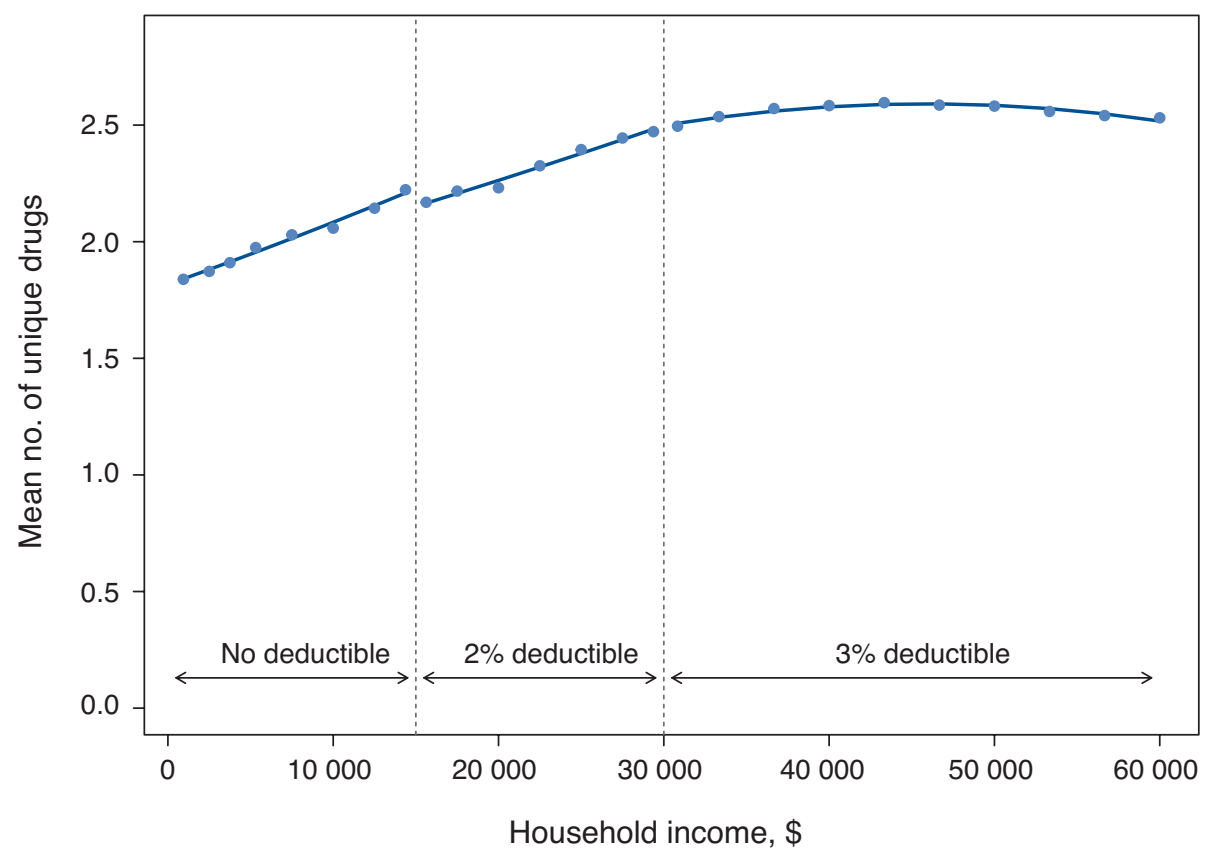

Figure 5: Regression discontinuity analysis of average annual number of unique drugs (Anatomical Therapeutic Chemical Classification System level 7) filled above and below the income thresholds.

deductibles. It is important to note, however, that private insurance does cover $60 \%$ of Canadians, ${ }^{20}$ and, thus, we feel that our results represent the true impact of income-based deductibles in Canada. In addition, we feel that the presence of employer-based coverage would likely not have biased our results, as there is no reason to believe that there is an abrupt 
change in private coverage at a household income of $\$ 15000$ or $\$ 30000$. This also precluded our ability to examine changes in out-of-pocket payments across the income thresholds. Our analysis was restricted to those who were registered for Fair PharmaCare. Although it is unknown whether there are sociodemographic differences between those who register and those who do not, lower-income people without private insurance are more likely than those with higher incomes to rely on public drug programs. Thus, this restriction is unlikely to have biased our significant result at the $\$ 15000$ threshold. Finally, we were unable to assess the impact of deductibles on patient outcomes or the use of other health care services.

\section{Conclusion}

Our results suggest that public drug coverage programs should be cognizant of how using income-based deductibles may affect the members of their plans. In particular, our results show that the current use of deductibles is offsetting significant public expenditure in BC. Furthermore, this is having an impact on prescription drug use for households with low incomes, reducing it by an estimated $7.2 \%$, but an increase in the deductible at a higher income level did not have a similar impact. Moves in the US to cover first-line medicines for chronic conditions - so-called value-based insurance designs - might provide a model for how to exempt certain classes from deductibles to avoid this type of impact. ${ }^{21,22}$ Moreover, it will be important to assess the impact of changes to the deductible structure by the $\mathrm{BC}$ government that will increase the threshold for the imposition of deductibles to $\$ 30000$ on Jan. 1, 2019.

\section{References}

1. Daw JR, Morgan SG. Stitching the gaps in the Canadian public drug coverage patchwork? A review of provincial pharmacare policy changes from 2000 to 2010. Health Policy 2012;104:19-26.

2. Law MR, Cheng L, Dhalla IA, et al. The effect of cost on adherence to prescription medications in Canada. CMA7 2012;184:297-302.

3. Tamblyn R, Laprise R, Hanley JA, et al. Adverse events associated with prescription drug cost-sharing among poor and elderly persons. FAMA 2001;285:421-9.

4. Goldman, Joyce GF, Zheng Y. Prescription drug cost sharing: associations with medication and medical utilization and spending and health. FAMA 2007; 298:61-9.

5. Dormuth CR, Maclure M, Glynn RJ, et al. Emergency hospital admissions after income-based deductibles and prescription copayments in older users of inhaled medications. Clin Ther 2008;30:1038-50.

6. Morgan S, Evans R, Hanley G, et al. Income-based drug coverage in British Columbia: lessons for BC and the rest of Canada. Healthc Policy 2006;2:115-27.

7. Kozyrskyj AL, Mustard CA, Cheang MS, et al. Income-based drug benefit policy: impact on receipt of inhaled corticosteroid prescriptions by Manitoba children with asthma. CMAf 2001;165:897-902.

8. Law MR, Cheng L, Worthington H, et al. Impact of income-based deductibles on drug use and health care utilization among older adults. CMAf 2017;189: E690-6.

9. Fronstin P, Sepúlveda MJ, Roebuck MC. Consumer-directed health plans reduce the long-term use of outpatient physician visits and prescription drugs. Health Aff (Millwood) 2013;32:1126-34.

10. Morgan SG, Daw JR, Law MR. Are income-based public drug benefit programs fit for an aging population? no 50 of IRPP Study series. Montréal: Institute for Research on Public Policy; 2014. Available: http://irpp.org/research-studies/ study-no50/ (accessed 2015 Jan. 19).

11. Busby C, Pedde J. Should public drug plans be based on age or income? no 417 of C.D. Howe Institute Commentary series. Toronto: C.D. Howe Institute; 2014.
Available: https://www.cdhowe.org/sites/default/files/attachments/research_ papers/mixed/Commentary_417.pdf (accessed 2015 Jan. 19).

12. Census profile, 2016 census: British Columbia [province] and Canada [country]. Ottawa: Statistics Canada; 2017. Available: https://www12.statcan.gc.ca/ census-recensement/2016/dp-pd/prof/details/Page.cfm?Lang=E\&Geo1=PR\& Code $1=59 \&$ Geo $2=\&$ Code $2=\&$ Data $=$ Count $\&$ Search Text $=$ British $\% 20$ Columbia $\&$ Search Type $=$ Begins $\&$ SearchPR $=01 \& B 1=$ All $\&$ GeoLevel $=P R \&$ GeoCode $=59$ (accessed 2019 Mar. 20).

13. PharmaCare trends 2016/17 [Internet]. Victoria: British Columbia Ministry of Health; 2018. Available: https://www2.gov.bc.ca/assets/gov/health/health -drug-coverage/pharmacare/pharmacare-trends-2016-17.pdf (accessed 2018 July 19).

14. O'Keeffe AG, Geneletti S, Baio G, et al. Regression discontinuity designs: an approach to the evaluation of treatment efficacy in primary care using observational data. BM7 2014;349:g5293.

15. Moscoe E, Bor J, Bärnighausen T. Regression discontinuity designs are underutilized in medicine, epidemiology, and public health: a review of current and best practice. 7 Clin Epidemiol 2015;68:122-33.

16. Venkataramani AS, Bor J, Jena AB. Regression discontinuity designs in healthcare research. $B M 7$ 2016;352:11216.

17. Bor J, Moscoe E, Mutevedzi P, et al. Regression discontinuity designs in epidemiology. Epidemiology 2014;25:729-37.

18. Smith LM, Kaufman JS, Strumpf EC, et al. Effect of human papillomavirus (HPV) vaccination on clinical indicators of sexual behaviour among adolescent girls: the Ontario Grade 8 HPV Vaccine Cohort Study. CMA7 2015;187: E74-81.

19. Law MR, Cheng L, Kolhatkar A, et al. The consequences of patient charges for prescription drugs in Canada: a cross-sectional survey. CMA7 Open 2018;6: E63-70.

20. Allin S, Law MR, Laporte A. How does complementary private prescription drug insurance coverage affect seniors' use of publicly funded medications? Health Policy 2013;110:147-55.

21. Choudhry NK, Avorn J, Glynn RJ, et al.; Post-Myocardial Infarction Free Rx Event and Economic Evaluation (MI FREEE) Trial. Full coverage for preventive medications after myocardial infarction. N Engl 7 Med 2011;365:2088-97.

22. Chernew ME, Juster IA, Shah M, et al. Evidence that value-based insurance can be effective. Health Aff (Millwood) 2010;29:530-6.

Affiliations: Centre for Health Services and Policy Research (Law, Cheng, Worthington, McGrail, Chan, Laba), School of Population and Public Health, University of British Columbia, Vancouver, BC; Department of Medicine (Majumdar), University of Alberta, Edmonton, Alta.; Menzies Centre for Health Policy (Laba), Faculty of Medicine and Health, University of Sydney, Sydney, Australia; Centre for Clinical Epidemiology and Evaluation (Laba), University of British Columbia, Vancouver, BC; Li Ka Shing Centre for Healthcare Analytics Research and Training (Mamdani), St. Michael's Hospital, Toronto, Ont.

Contributors: Michael Law conceived of the study, acquired the data and drafted the manuscript. Sumit Majumdar, Kimberlyn McGrail, Fiona Chan, Tracey-Lea Laba and Muhammad Mamdani made substantial contributions to the design of the work. Lucy Cheng and Heather Worthington analyzed the data. Lucy Cheng, Heather Worthington, Sumit Majumdar, Kimberlyn McGrail, Fiona Chan, Tracey-Lea Laba and Muhammad Mamdani revised the manuscript for important intellectual content. All of the authors interpreted the data, gave final approval of the version to be published and agreed to act as guarantors of the work.

Funding: This analysis was funded by a research grant from the Institute for Health System Transformation and Sustainability. Michael Law received salary support through a Canada Research Chair and a Michael Smith Foundation for Health Research Scholar Award. Sumit Majumdar held the Endowed Chair in Patient Health Management, supported by the Faculties of Medicine and Dentistry and of Pharmacy and Pharmaceutical Sciences, University of Alberta.

Disclaimer: Data for this study were obtained via Population Data BC, including data from the BC PharmaNet system. All inferences, opinions and conclusions drawn in this publication are those of the authors and do not reflect the opinions of Population Data BC or the data steward(s).

Supplemental information: For reviewer comments and the original submission of this manuscript, please see www.cmajopen.ca/content/7/1/ E167/suppl/DC1. 